\title{
Microsatellite instability and clinicopathological features in esophageal squamous cell cancer
}

\author{
YUSUKE MATSUMOTO $^{1}$, TAKESHI NAGASAKA ${ }^{1}$, TAKESHI KAMBARA $^{1}$, NAOKO HOSHIZIMA ${ }^{1}$, \\ JUN MURAKAMI ${ }^{4}$, HIROMI SASAMOTO ${ }^{1}$, MASAO HOSOKAWA ${ }^{2}$, YOSHIO NAOMOTO ${ }^{1}$, \\ HIROSHI ISOZAKI $^{1}$, KENJI SHIMIZU ${ }^{3}$, NORIAKI TANAKA ${ }^{1}$ and NAGAHIDE MATSUBARA ${ }^{1}$ \\ ${ }^{1}$ Department of Gastroenterological Surgery and Surgical Oncology, Okayama University Graduate School of Medicine \\ and Dentistry, Okayama 700-8558; ${ }^{2}$ The Keiyuukai-Sapporo Hospital, Sapporo; ${ }^{3}$ Department of Molecular \\ Genetics and ${ }^{4}$ Department of Oral and Maxillofacial Radiology, Okayama University \\ Graduate School of Medicine and Dentistry, Okayama 700-8558, Japan
}

Received June 6, 2007; Accepted July 23, 2007

\begin{abstract}
Since multiple genetic alterations are involved in the molecular pathogenesis of esophageal squamous cell cancer (ESCC), the role of microsatellite instability (MSI) in its carcinogenesis is not well defined. The reported frequency of MSI in ESCC ranges from 2 to $66.7 \%$ but the majority of the results are derived from relatively small studies. Therefore, we carried out a precise MSI analysis on a large number of ESCC samples to clarify the significance of MSI in the ESCC tumorigenesis. The MSI status of the DNA extracted from 62 ESCC samples and 62 counterpart-normal esophageal epitheliums were studied with five NCI panel markers and ten microsatellite markers located in 17q24-25. Forty-four paraffin-embedded samples and 18 frozen samples from the ESCC patients who underwent surgery were studied. The MSI status was classified as MSS (microsatellite stable), MSI-L (low-level MSI; $<30 \%$ of markers examined showed instability) and MSI-H (high-level MSI; $>30 \%$ of markers reported instability). Among the 62 ESCC cases analyzed by the 15 microsatellite markers, 38 out of 62 cases $(61.3 \%)$ showed MSS, 19 out of 62 cases (30.6\%) showed MSI-L and
\end{abstract}

Correspondence to: Dr Nagahide Matsubara, Department of Gastroenterological Surgery and Surgical Oncology, Okayama University Graduate School of Medicine, Dentistry and Pharmaceutical Sciences, 2-5-1 Shikata-cho, Okayama 700-8558, Japan

E-mail: nagamb@cc.okayama-u.ac.jp

Abbreviations: ESCC, esophageal squamous cell cancer; MSI, microsatellite instability; MSS, microsatellite stable; MSI-L, lowlevel microsatellite instability; MSI-H, high-level microsatellite instability; HNPCC, hereditary non-polyposis colorectal cancer; MGMT, $\mathrm{O}^{6}$-methylguanine DNA methyltransferase; MMR, mismatch repair

Key words: esophageal squamous cell cancer, microsatellite instability, depth of invasion, prognosis, early stage
5 out of 62 cases $(8.1 \%)$ showed MSI-H. Although the MSI status was not associated with the status of lymph node metastasis or a histological type of cancer, the depth of cancer invasion was significantly associated with the frequency of MSS status and the levels of MSI-L were inversely correlated with the depth of invasion (T1/T2 vs. T3/4; $\mathrm{P}=0.0007)$. However, MSI status was not associated with the prognosis of the ESCC patients. This is the first large scale MSI analysis of the ESCC in comparison with the clinicopathological features. Relatively high frequency of MSI-L was observed in ESCC and the frequency of MSI-L was inversely correlated with the depth of invasion.

\section{Introduction}

Esophageal cancer is a frequent fatal cancer throughout the world (1). Squamous cell carcinoma and adenocarcinoma are the two major pathological types in esophageal cancer. Despite the increased incidence of esophageal adenocarcinoma in North America and Europe, esophageal squamous cell cancer (ESCC) remains a common type of malignancy worldwide (1). Tobacco and alcohol consumption represent major environmental risk factors, however, the molecular events leading to the ESCC are largely unknown (2).

High-level microsatellite instability (MSI-H), which is defined as $>30 \%$ of microsatellite markers showing instability in tumor DNA $(6,7)$, has been described in hereditary nonpolyposis colorectal cancer (HNPCC) and in 15 to $20 \%$ of sporadic colorectal cancers (3-5). In colorectal cancer, MSI-H correlates well with the proximal colon location, mucinous and poorly differentiated histology and better prognosis $(6,7)$. In sporadic MSI-H colorectal cancer, the silencing of $h M L H 1$ through promoter hypermethylation is the main mechanism for its mismatch repair defect (8-10). Low-level microsatellite instability (MSI-L) is defined as $<30 \%$ of markers showing instability $(11,12)$. No clear clinical or pathologic differences were noted between MSI-L and microsatellite stable (MSS) tumors $(12,13)$. Since MSI-L phenotype is not well defined, MSI-L has been frequently considered as MSS. We observed previously that MSI-L phenotype was frequently detected in 
early colorectal cancers compared with advanced ones and we proposed that MSI-L phenotype is a separate category in colorectal cancer (14).

In ESCC, MSI has not been considered as a major event in its tumorigenesis. According to the relatively small studies, the frequency of MSI in ESCC is in a range of 2 to $66.7 \%$ (1522). To clarify the true significance in pathogenesis of ESCC, we analyzed the precise MSI status of the disease in a largescale study.

\section{Materials and methods}

Patients. Sixty-two patients with ESCC, who underwent a curative esophagectomy at the Okayama University Hospital (18 patients) between 1995 to 1998 and the Keiyuukai Sapporo Hospital (44 patients) in 1994, were collected after obtaining informed consent from all the patients. None of the patients received any preoperative chemotherapy or radiation. The patients included 58 men and 4 women ranging in age from 45-80 years (mean age 63.2 years). None of them had a hereditary background of ESCC.

DNA extraction. The genomic DNA from 18 patients from the Okayama University Hospital was obtained from the frozen tumor specimens and matched normal mucosal tissue specimens using phenol-chloroform extraction after proteinase $\mathrm{K}$ treatment. The genomic DNA was extracted from paraffin-embedded tissue derived from the 44 patients treated at the Keiyuukai Sapporo Hospital by a microdissection technique. DNA was also extracted from paraffin-embedded non-malignant stromal tissue on the same block by a microdissection technique.

Microsatellite analysis. The MSI status of the DNA extracted from ESCC and from counterpart normal tissue was determined by a panel of 15 markers using the fluorescence autosequencer (SQ-5500E, Hitachi Co., Tokyo, Japan). Five primers (BAT25, BAT26, D2S123, D5S346 and D17S250) were the NCI recommended panel for MSI (12). Ten primers were located on 17q24-25, aimed at searching for the novel tumor suppressor gene. Seven primers (D17S949, D17S1862, D17S1352, D17S709, D17S650,D17S785 and D17S939) were available through an Internet genome database and 3 primers (17q25MS1, 17q25MS2 and 17q25MS3) were our designed markers (Table I). PCR was performed in $50 \mu 1$ reaction mixtures comprising of $3 \mu \mathrm{l}$ of the 5X DNA sample, $9 \mu \mathrm{l}$ of Gene Releaser (Bio Ventures Inc. Murfreesboro, TN), $0.3 \mu \mathrm{M}$ of each oligonucleotide primer pair (one end-labeled with Texas Red), $200 \mathrm{mM}$ each dNTPs, $5 \mu 1$ of 10X PCR buffer and 1.25 unit of Taq polymerase (Ampli-TaqGold, PerkinElmer, Foster City, CA). After denaturation by formaldehyde at $95^{\circ} \mathrm{C}$ for $5 \mathrm{~min}$, the amplified PCR products were electrophoresed on a 6\% LongRanger-6.1 M urea gel on Autosequencer SQ-5500 and analyzed by FRAGRYS version 2 software (Hitachi Inc., Tokyo, Japan). MSI was classified as MSS, MSI-L; $<30 \%$ of markers examined showed instability and MSI-H; $>30 \%$ of markers showed instability.

Statistical analysis. The Chi-square and Wilcoxon/KruskalWallis tests were performed using software JMP 5.0.1 J
Table I. Microsatellite markers used in this study.

\begin{tabular}{lccc}
\hline Markers & Repeat & $\begin{array}{c}\text { Product } \\
\text { length (bp) }\end{array}$ & Locus \\
\hline BAT25 & mono-nucleotide & 125 & $4 \mathrm{q} 12$ \\
BAT26 & mono-nucleotide & 122 & $2 \mathrm{p} 16$ \\
D5S346 & di-nucleotide & 138 & $5 \mathrm{q} 21-5 \mathrm{q} 22$ \\
D17S250 & di-nucleotide & 163 & $17 \mathrm{q} 11.2-17 \mathrm{q} 12$ \\
$D 2 S 123$ & di-nucleotide & 140 & $2 \mathrm{p} 16$ \\
$D 17 S 949$ & di-nucleotide & 191 & $17 \mathrm{q} 24$ \\
$D 17 S 1862$ & di-nucleotide & 145 & $17 \mathrm{q} 24$ \\
D17S1352 & di-nucleotide & 143 & $17 \mathrm{q} 25$ \\
D17S709 & di-nucleotide & 106 & $17 \mathrm{q} 25$ \\
D17S650 & di-nucleotide & 119 & $17 \mathrm{q} 25$ \\
$17 q 25 M S 3$ & di-nucleotide & 152 & $17 \mathrm{q} 25$ \\
$17 q 25 M S 1$ & di-nucleotide & 164 & $17 \mathrm{q} 25$ \\
$17 q 25 M S 2$ & di-nucleotide & 120 & $17 \mathrm{q} 25$ \\
$D 17 S 785$ & di-nucleotide & 175 & $17 \mathrm{q} 25$ \\
D17S939 & di-nucleotide & 122 & $17 \mathrm{q} 25.3$ \\
\hline
\end{tabular}

software (SAS Institute Inc., NC). $\mathrm{P}<0.05$ was considered to be statistically significant.

\section{Results and discussion}

We collected 62 ESCC samples and analyzed the MSI status. Fig. 1A demonstrates a histological section of ESCC with submucosal invasion before and after microdissection. Microdissection of a cancer rich area was carefully performed in order to minimize the amount of contaminating normal tissue and stroma. Fifteen microsatellite markers were used to determine the MSI status (Fig. 1B). Interpretation of the microsatellite analysis was performed by two independent experts on fragment analysis. If agreement was not reached, re-analysis of the samples was undertaken. Among the 62 ESCC cases analyzed, 38 out of 62 cases $(61.3 \%)$ showed MSS, 19 out of 62 cases $(30.6 \%)$ showed MSI-L and 5 out of 62 cases $(8.1 \%)$ showed MSI-H.

Association of MSI status with clinicopathological features in a total of 62 ESCCs are shown in Table II. Although the MSI status was not associated with the status of lymph node metastasis or a histological type of cancer, the depth of invasion was significantly related to the frequency of MSS status and MSI-L was inversely correlated with the depth of invasion ( $\mathrm{P}=0.0007)$ (Fig. 2A-C). Although the depth of invasion is a factor involved in the altitude of stage, association of the stage level and MSI-L status reported the same trend observed in the depth of invasion, but was not remarkable (Fig. 2D). This was due to the fact that MSI-L cancers tend to reveal more lymph node metastasis within the same levels of stage. However, MSI status was not associated with the prognosis of the ESCC patients either in overall survival or disease-free survival (Fig. 3).

This is the first large scale MSI analysis of the ESCC and the results were compared with the clinicopathological features of the ESCC. In our study, the frequency of MSS, MSI-L and MSI-H in the ESCC were 61.3, 30.6, and 8.1\%, respectively. The incidence of MSI-H in the ESCC patients was $8.1 \%$ (5 out 


\section{Sample No.52}
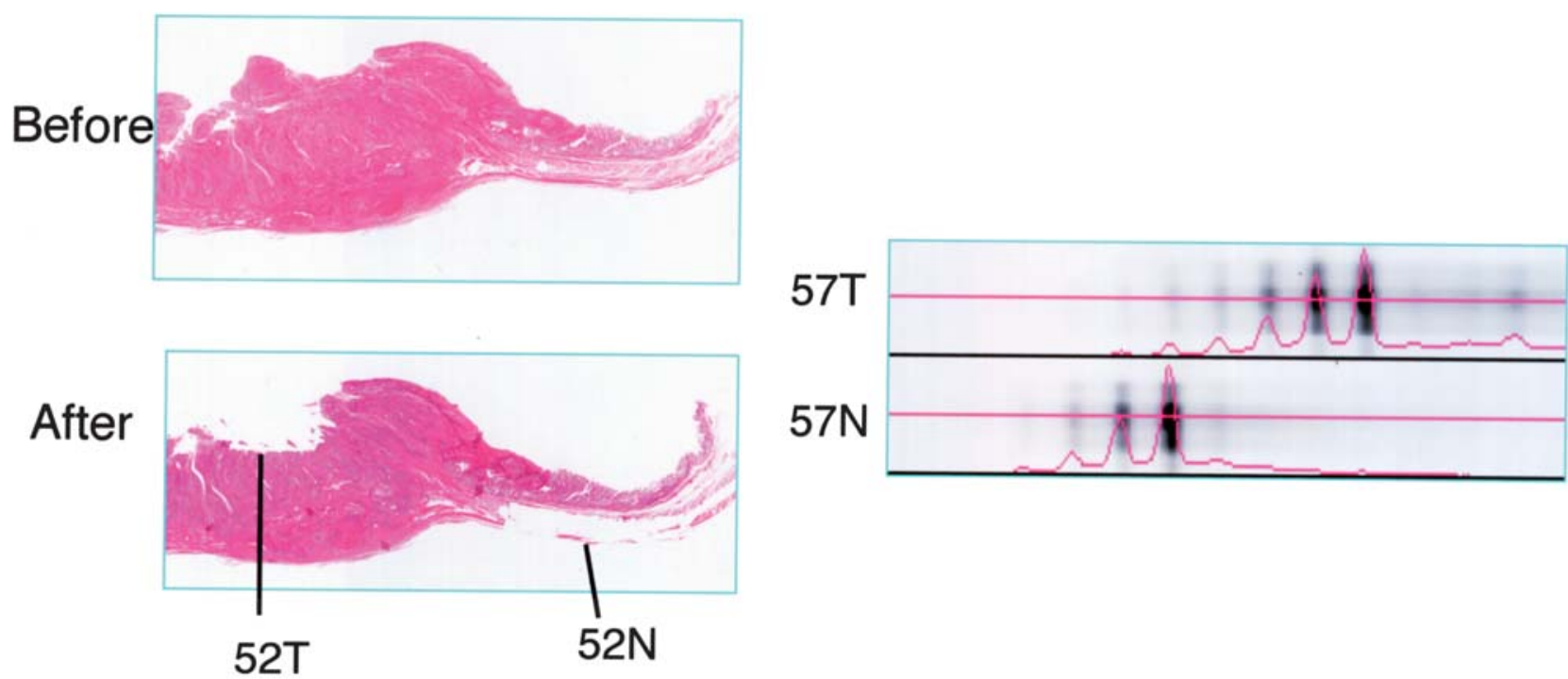

Figure 1. Microdissection of the paraffin-embedded esophageal samples and microsatellite instability analysis. (A) With the guide of H\&E stained slides, cancer regions were micro-dissected from paraffin-embedded esophageal samples. Non-cancerous tissue from the counterpart adjacent regions was also captured for the analysis. (B) Representative example of the results of the fluorescent microsatellite analysis of the DNA extracted from the tumor in comparison with the counterpart normal tissue. The sample (T57) shows microsatellite instability of the D17S250 in comparison with the normal counterpart (N57).

Table II. Microsatellite status vs clinicopathological features in esophageal squamous cell carcinoma.

\begin{tabular}{|c|c|c|c|c|c|}
\hline & Total $(\%)$ & MSS & MSI-L & MSI-H & $\mathrm{P}^{\mathrm{a}}$ \\
\hline \multicolumn{6}{|l|}{ Gender } \\
\hline Male & $58(93.5)$ & $36(62.1)$ & $18(31.0)$ & $4(6.9)$ & 0.5619 \\
\hline Female & $4(6.5)$ & $2(50.0)$ & $1(25.0)$ & $1(25.0)$ & \\
\hline Age & $63.2 \pm 7.6$ & $61.6 \pm 7.4$ & $65.8 \pm 7.5$ & $65.2 \pm 8.3$ & 0.2489 \\
\hline \multicolumn{6}{|l|}{ Tumor stage } \\
\hline Stage $0, \mathrm{I}$ & $11(17.7)$ & $5(45.5)$ & $6(54.5)$ & $0(0)$ & 0.0967 \\
\hline Stage II & $29(46.8)$ & $17(58.6)$ & $9(31.0)$ & $3(10.3)$ & \\
\hline Stage III & $22(35.5)$ & $16(72.7)$ & $4(18.2)$ & $2(9.1)$ & \\
\hline \multicolumn{6}{|c|}{ Pathological type } \\
\hline Well & $31(53.4)$ & $18(58.1)$ & $10(32.3)$ & $3(9.7)$ & 0.8017 \\
\hline Moderately & $23(39.7)$ & $14(60.9)$ & $8(34.8)$ & $1(4.3)$ & \\
\hline Poorly & $4(6.9)$ & $2(50.0)$ & $1(25.0)$ & $1(25.0)$ & \\
\hline \multicolumn{6}{|c|}{ Lymphnode metastasis } \\
\hline $\mathrm{n}(-)$ & $21(33.9)$ & $12(57.1)$ & $8(38.1)$ & $1(4.8)$ & 0.5723 \\
\hline $\mathrm{n}(+)$ & $41(66.1)$ & $26(68)$ & $11(58)$ & $4(80)$ & \\
\hline \multicolumn{6}{|c|}{ Depth of tumor invasion } \\
\hline $\mathrm{T} 1, \mathrm{~T} 2$ & $24(40)$ & $11(45.8)$ & $13(54.2)$ & $0(0)$ & 0.0007 \\
\hline $\mathrm{T} 3, \mathrm{~T} 4$ & $36(60)$ & $26(72.2)$ & $5(13.9)$ & $5(13.9)$ & \\
\hline
\end{tabular}

MSS, microsatellite stable; MSI-H, high-frequent microsatellite instability; MSI-L, low-frequent microsatellite instability; well, well-differentiated adenocarcinoma; moderately, moderately differentiated adenocarcinoma; poorly, poorly differentiated adenocarcinoma; $\mathrm{n}(-)$, free of lymph node metastasis; $\mathrm{n}$

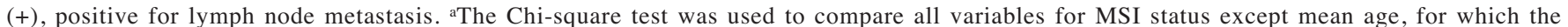
Wilcoxon/Kruskal-Wallis test was employed. 
A

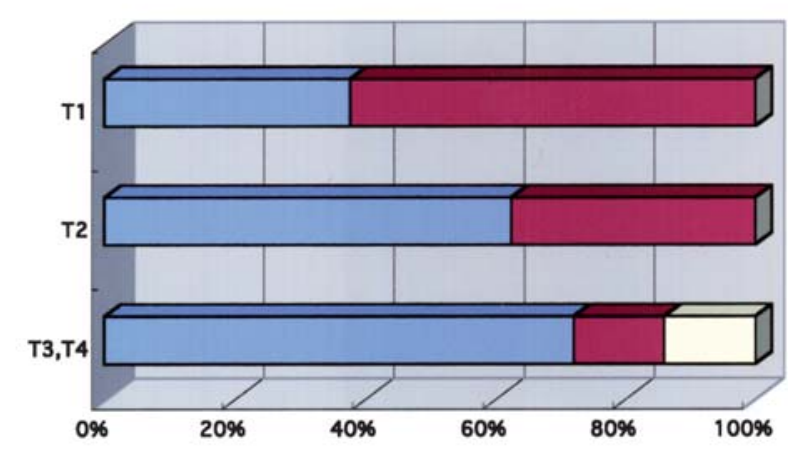

B

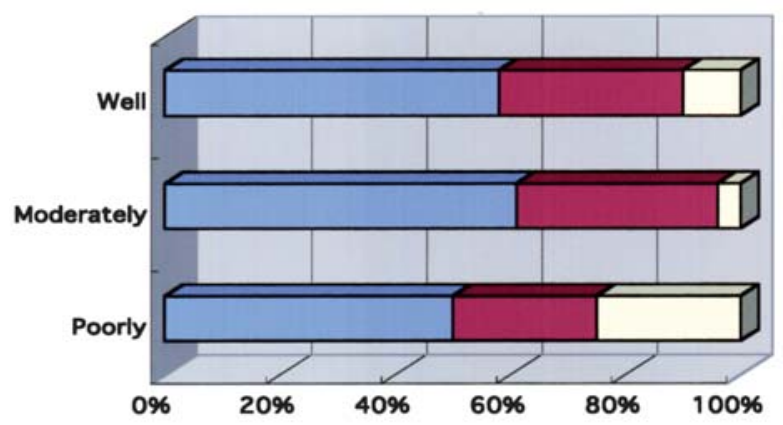

C

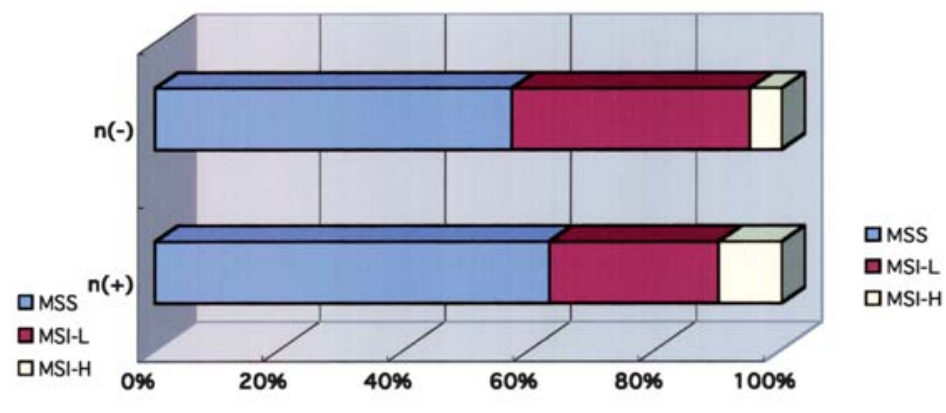

$\mathrm{D}$

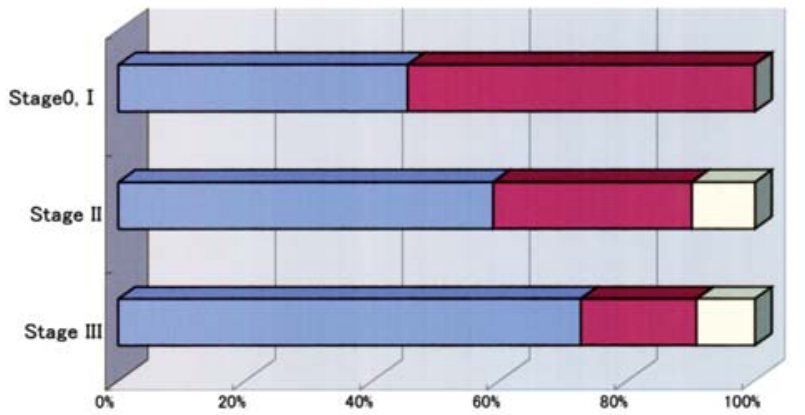

Figure 2. (A) Comparison of the frequency of MSS, MSI-L and MSI-H phenotype in differing depth of invasion of the esophageal squamous cell carcinoma (ESCC). The frequency of MSI-L in T1 ESCC was significantly higher than that in T2 and the same with T2 vs. T3, T4 ESCC. (B) Frequency of MSS, MSI-L and MSI-H phenotype between lymph node positive and negative ESCC. (C) Frequency of MSS, MSI-L and MSI-H phenotype between differing histology of the ESCC. No difference was observed between the histological types. (D) Comparison of the frequency of MSS, MSI-L and MSI-H phenotype at differing stages of the ESCC. Frequency of MSI-L is higher at stage 0 and I ESCC compared with stage II and III ESCC, but the difference was not statistically significant.

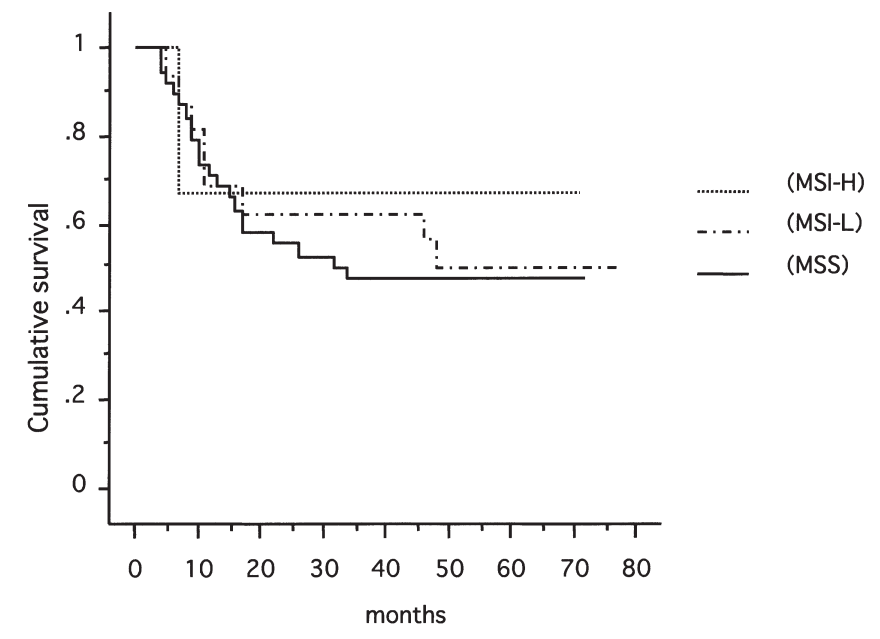

Figure 3. Differing overall survival of the ESCC patients by the MSI status.

of 62$)$ and correspond with the previous studies $(17,23,24)$. However, relatively high-levels of MSI-L status were observed in ESCC compared with the colorectal cancer or stomach cancers (14). The prevalence and the clinical significance of MSI-L in ESCC are poorly understood. In colorectal and stomach cancer, the MSI-L and MSS cancers are sometimes considered inseparable because of the lack of particular clinicopathological phenotype in MSI-L $(12,13)$. In our study, MSI-L status was significantly associated with the depth of invasion into the esophageal wall similarly to our observations in colorectal cancer cases (14). However, there was no difference in stage between MSI-L and MSS ESCC. Therefore, MSI-L was not different from MSS in overall or disease-free survival.

It is also noteworthy that MSI-H was only observed in T3 and T4 ESCC. This suggests that a subset of the MSI-L cancer may develop to MSI-H cancer along with the cancer invading the wall of the esophagus. Since progression of the MSI-L ESCC may be slow compared with that of the MSS, more MSI-L cancers are identified in the earlier sages.

A possible biological event causing MSI-L phenotype has gradually been revealed. Promoter methylation of the $O^{6}$ methylguanine DNA methyltransferase (MGMT) followed by the loss of MGMT expression has been related to the MSI-L phenotype in colorectal cancer $(25,26)$. MGMT is a DNA repair enzyme that rapidly repairs adducts at the $O^{6}$-position of guanine and acts with the mismatch repair (MMR) system. Almost $80 \%$ of the ESCC showed promoter methylation of $M G M T$ in our study (data not published), thus, loss of function of MGMT may affect the observed high frequency of MSI-L in our series of ESCC. It is also possible that the MSI-L observed in ESCC may not be directly due to the mismatch repair deficiency $(11,12,27)$, but rather be caused by other 
mechanisms that may affect the MMR system. Oxidative stress is one of the probable mechanisms that may affect the MMR system (28-30). The reactive oxygen species produced in the environment of chronically inflamed esophageal epithelium may lead to DNA damage. Over-production of free radicals saturates the ability of cells to repair DNA damage prior to replication. The resulting imbalance in base excision-repair enzymes may cause MSI-L in chronic inflammation (31).

In conclusion, a relatively high frequency of MSI-L was observed in ESCC and the frequency of MSI-L was inversely associated with the depth of invasion. However, the presence of MSI-L did not correlate with other clinicopathological features such as tumor stage, degree of differentiation, or the presence of lymph node metastasis. There was no correlation between the presence of MSI and survival. A fraction of the MSI-L cancer cells observed at an early stage of ESCC might develop in the MSI-H cells at a later stage of cancer development.

\section{References}

1. Parkin DM, Pisani P and Ferlay J: Estimates of the worldwide incidence of 25 major cancers in 1990. Int J Cancer 80: 827-841, 1999.

2. Kuwano H, Kato H, Miyazaki T, Fukuchi M, Masuda N, Nakajima M, Fukai Y, Sohda, M, Kimura H and Faried A: Genetic alterations in esophageal cancer. Surg Today 35: 7-18, 2005.

3. Peltomäki P, Lothe RA, Aaltonen LA, Pylkkänen L, Nyström-Lahti M, Seruca R, David L, Holm R, Ryberg D, Haugen A, Brøgger A, Børresen AL and de la Chapelle A: Microsatellite instability is associated with tumors that characterize the hereditary non-polyposis colorectal carcinoma syndrome. Cancer Res 53: 5853-5855, 1993.

4. Shibata D, Peinado MA, Ionov Y, Malkhosyan S and Perucho M: Genomic instability in repeated sequences is an early somatic event in colorectal tumorigenesis that persists after transformation. Nat Genet 6: 273-281, 1994.

5. Ionov Y, Peinado MA, Malkhosyan S, Shibata D and Perucho M: Ubiquitous somatic mutations in simple repeated sequences reveal a new mechanism for colonic carcinogenesis. Nature 363: 558-561, 1993.

6. Kim H, Jen J, Vogelstein B and Hamilton S: Clinical and pathological characteristics of sporadic colorectal carcinomas with DNA replication errors in microsatellite sequences. Am J Pathol 145: 148-156, 1994.

7. Lothe R, Peltomaki P, Meling G, Aaltonen L, Nystrom-Lahti M and Pylkkanen L: Genomic instability in colorectal cancer: relationship to clinicopathologic variables and family history. Cancer Res 53: 5849-5852, 1993.

8. Kane MF, Loda M, Gaida GM, Lipman J, Mishra R, Goldman H, Jessup JM and Kolodner RD: Methylation of the hMLH1 promoter correlates with lack of expression of hMLH1 in sporadic colon tumors and mismatch repair-defective human tumor cell lines. Cancer Res 57: 808-811, 1997.

9. Herman J, Umar A, Polyak K, Graff J, Ahuja N, Issa J, Markowitz S, Willson J, Hamilton S, Kinzler K, Kane M, Kolodner R, Vogelstein B, Kunkel T and Baylin S: Incidence and functional consequences of $h M L H 1$ promoter hypermethylation in colorectal carcinoma. Proc Natl Acad Sci USA 95: 6870-6875, 1998.

10. Cunningham JM, Christensen ER, Tester DJ, Kim C, Roche PC, Burgart LJ, Thibodeau SN: Hypermethylation of the $h M L H 1$ promoter in colon cancer with microsatellite instability. Cancer Res 58: 3455-3460, 1998.

11. Dietmaier W, Wallinger S, Bocker T, et al: Diagnostic microsatellite instability: Definition and correlation with mismatch repair protein expression. Cancer Res 57: 4749-4756, 1997.

12. Boland CR, Thibodeau SN, Hamilton SR, et al: A National Cancer Institute Workshop on microsatellite instability for cancer detection and familial predisposition: Development of international criteria for the determination of microsatellite instability in colorectal cancer. Cancer Res 58: 5248-5257, 1998.
13. Wu MS, Lee CW, Shun CT, Wang HP, Lee WJ, Chang MC, Sheu JC and Lin JT: Distinct clinicopathologic and genetic profiles in sporadic gastric cancer with different mutator phenotypes. Genes Chromosomes Cancer 27: 403-411, 2000.

14. Kambara T, Matsubara N, Nakagawa H, Notohara K, Nagasaka T, Yoshino T, Isozaki H, Sharp GB, Shimizu K, Jass J and Tanaka N: High frequency of low-level microsatellite instability in early colorectal cancer. Cancer Res 61: 7743-7746, 2001.

15. Kagawa Y, Yoshida K, Hirai T, Toge T, Yokozaki H, Yasui W and Tahara E: Microsatellite instability in squamous cell carcinoma and dysplasia of the esophagus. Anticancer Res 20: 213-217, 2000.

16. Meltzer SJ, Yin J, Manin B, Rhyu MG, Cottrell J, Hudson E, Redd JL, Krasna MJ, Abraham JM and Reid BJ: Microsatellite instability occurs frequently and in both diploid and aneuploid cell populations of Barrett's-associated esophageal adenocarcinomas. Cancer Res 54: 3379-3382, 1994.

17. Muzeau F, Flejou JF, Belghiti J, Thomas G and Hamelin R: Infrequent microsatellite instability in oesophageal cancers. Br J Cancer 75: 1336-1339, 1997.

18. Nakashima H, Mori M, Mimori K, Inoue H, Shibuta K, Baba K, Mafune $\mathrm{K}$ and Akiyoshi T: Microsatellite instability in Japanese esophageal carcinoma. Int J Cancer 64: 286-289, 1995.

19. Mironov NM, Aguelon AM, Hollams E, Lozano JC and Yamasaki H: Microsatellite alterations in human and rat esophageal tumors at selective loci. Mol Carcinog 13: 1-5, 1995.

20. Wang L, Li W, Wang X, Zhang C, Zhang T, Mao X and Wu M: Genetic alterations on chromosomes 3 and 9 of esophageal cancer tissues from China. Oncogene 12: 699-703, 1996.

21. Hayashi M, Tamura G, Jin Z, Kato I, Sato M, Shibuya Y, Yang S and Motoyama T: Microsatellite instability in esophageal squamous cell carcinoma is not associated with $h M L H 1$ promoter hypermethylation. Pathol Int 53: 270-276, 2003.

22. Mathew R, Arora S, Mathur M, Chattopadhyay TK and Ralhan R: Esophageal squamous cell carcinomas with DNA replication errors (RER+) are associated with p16/pRb loss and wild-type p53. J Cancer Res Clin Oncol 127: 603-612, 2001.

23. Hu N, Roth MJ, Polymeropolous M, Tang ZZ, Emmert-Buck MR, Wang QH, Goldstein AM, Feng SS, Dawsey SM, Ding T, Zhuang ZP, Han XY, Reid T, Giffen C and Taylor PR: Identification of novel regions of allelic loss from a genomewide scan of esophageal squamous-cell carcinoma in a high-risk Chinese population. Genes Chromosomes Cancer 27: 217-228, 2000.

24. Hu N, Roth MJ, Emmert-Buck MR, Tang ZZ, Polymeropolous M, Wang QH, Goldstein AM, Han XY, Dawsey SM, Ding T, Giffen C and Taylor PR: Allelic loss in esophageal squamous cell carcinoma patients with and without family history of upper gastrointestinal tract cancer. Clin Cancer Res 5: 3476-3482, 1999.

25. Whitehall VLJ, Walsh MD, Young J, Leggett BA and Jass JR: Methylation of O-6-methylguanine DNA methyltransferase characterizes a subset of colorectal cancer with low-level DNA microsatellite instability. Cancer Res 61: 827-830, 2001.

26. Mori Y, Selaru FM, Sato F, Yin J, Simms LA, Xu Y, Olaru A, Deacu E, Wang S, Taylor JM, Young J, Leggett B, Jass JR, Abraham JM, Shibata D and Meltzer SJ: The impact of microsatellite instability on the molecular phenotype of colorectal tumors. Cancer Res 63: 4577-4582, 2003.

27. Thibodeau SN, French AJ, Cunningham JM, Tester D, Burgart LJ, Roche PC, McDonnell SK, Schaid DJ, Vockley CW, Michels VV, Farr GH Jr and O'Connell MJ: Microsatellite instability in colorectal cancer: different mutator phenotypes and the principal involvement of hMLH1. Cancer Res 58: 1713-1718, 1998.

28. Jackson AL, Chen R and Loeb LA: Induction of microsatellite instability by oxidative DNA damage. Proc Natl Acad Sci USA 95: 12468-12473, 1998 .

29. Gasche C, Chang CL, Rhees J, Goel A and Boland CR: Oxidative stress increases frameshift mutations in human colorectal cancer cells. Cancer Res 61: 7444-7448, 2001.

30. Chang CL, Marra G, Chauhan DP, Ha HT, Chang DK, Ricciardiello L, Randolph A, Carethers JM and Boland CR: Oxidative stress inactivates the human DNA mismatch repair system. Am J Physiol Cell Physiol 283: C148-C154, 2002.

31. Hofseth LJ, Khan MA, Ambrose M, Nikolayeva O, Xu-Welliver M, Kartalou M, Hussain SP, Roth RB, Zhou X, Mechanic LE, Zurer I, Rotter V, Samson LD and Harris CC: The adaptive imbalance in base excision-repair enzymes generates microsatellite instability in chronic inflammation. J Clin Invest 112: 1887-1894, 2003. 